\title{
Intervención psicosocial en gestión de riesgo: utilización de nuevas tecnologías para la integración de los saberes populares y académicos
}

\author{
Diego Raúl Piñeyro* \\ Susana Celeste Azzollini** \\ Pablo Osvaldo Ruiz*** \\ Carlos Alexandre Bastos de Vasconcelos****
}

Recibido el 25 de febrero 2016; aceptado el 22 de septiembre de 2016

\begin{abstract}
Through an agreement with the National University of Catamarca (UNCa), the Center for Social and Human Research Defense (CISOHDEF), conducted a psychosocial intervention program in the town of "El Rodeo" (Catamarca, Argentina) where a team of psychologists Army with the help of social workers of the UNCa, worked with the community on organizational tasks, resilience and assistance to victims of a flood emergency.

This community recently suffered the biggest flood in its history by a flood of Ambato river, which dragged stones up to 3 tons in its route washed away cars, houses, bridges. This event left 11 dead, 1 missing, and at least a hundred people injured and experienced different conditions resulting from stress.
\end{abstract}

* Magister en Psicología Cognitiva, Centro de Investigaciones Sociales y Humanas para la Defensa, Facultad del Ejército Argentino, Universidad de la Defensa Nacional, CABA, Buenos Aires, Argentina, correo electrónico: diegopiney@gmail.com

** Doctora en Psicología, Centro de Investigaciones Sociales y Humanas para la Defensa, Secretaría de Ciencia y Técnica de la Facultad del Ejército Argentino, Universidad de la Defensa Nacional, CABA, Buenos Aires, Argentina

*** Licenciado en Estrategia y Organización, secretario de extensión de la Facultad del Ejército Argentino, Universidad de la Defensa Nacional, CABA, Buenos Aires, Argentina.

****Doctor en Ingeniería Civil en Recursos Hídricos por la Universidad Federal de Río de Janeiro, Brasil; pós-doutorado en Ingeniería Civil por la Universidad de Coimbra, Portugal. Docente extranjero de la Escuela Superior Técnica-Facultad del Ejército Argentino, Universidad de la Defensa Nacional, correo electrónico: cvasconcellos@est.iue.edu.ar 
Community workshops were conducted to establish comprehensive strategies coping, integrating the knowledge of the people (baqueanos that are people that are familiar with the terrain, firefighters and citizens who voluntarily collaborated in assisting victims of last flood) and experts in the field of Geography, Hydrology, Engineering civil and Public Health.

Local leaders were prepared in Psychological First Help. Pychologists received courses for the use of cognitive behavioral therapy in anxiety disorders. Academic and popular knowledge were integrated using the computer application (geographic information system of Google Earth) for the preparation of an emergency response protocol.

Key words: GIS, First aid floods, Psychological Post-traumatic stress.

\section{Resumo}

O Centro de Pesquisa Humanas e Sociais para Defesa (CISOHDEF) por intermédio de um acordo com a Universidade Nacional de Catamarca (UNCa), realizou um programa de intervenção psicossocial na cidade de El Rodeo, província de Catamarca, Argentina, onde uma equipe de psicólogos do Exército com a ajuda de assistentes sociais da UNCa, trabalhou com a comunidade em tarefas de organização, capacidade de recuperação e assistência às vítimas de uma situação de emergência por inundação. Esta comunidade sofreu, recentemente, a maior enchente de sua história por inundação do rio Ambato, onde se arrastaram pedras de até três toneladas em seu leito, levando carros, casas, pontes, e deixando onze mortos, um desaparecido e quase uma centena de pessoas feridas, que passaram diferentes condições de estresse. O referido Centro realizaram cursos comunitários que ensinam a elaborar estratégias abrangentes de enfrentamento desses casos, integrando o conhecimento de pessoas locais, que conhecem bem a sua região e que atuaram no episódio citado como voluntários, colaborando com a assistência às vítimas, com especialistas na área de Geografia, Hidrologia, Engenharia Civil e Saúde Pública. Esses cursos prepararam os líderes locais para atender suas comunidades com a Primeira Ajuda Psicológica. Além disso, psicólogos foram preparados para a utilização da terapia comportamental cognitiva por motivo de desordens de ansiedade nesses casos, agregando o conhecimento acadêmico e o popular, por meio de ferramentas computacionais (sistema de informação geográfica do Google Earth) com a finalidade de preparar de um protocolo de resposta de emergência.

Palavras-chave: SIG, Inundações, Primeira ajuda psicológica, Estresse póstraumático. 


\section{Resumen}

A través de un convenio con la Universidad Nacional de Catamarca (UNCa), el Centro de Investigaciones Sociales y Humanas para la Defensa (CISOHDEF), llevó adelante un programa de intervención psicosocial en la localidad de "El Rodeo" (Catamarca, Argentina), donde un equipo de psicólogos del Ejército con la colaboración de asistentes sociales de la UNCa, trabajó junto con la comunidad en tareas de organización, resiliencia y asistencia a víctimas de una emergencia por inundación.

Esta comunidad sufrió recientemente la inundación más importante de su historia por una crecida del río Ambato, el cual arrastró piedras de hasta tres toneladas que en su recorrido arrasaron con autos, casas, puentes, dejando un saldo de 11 muertos, un desaparecido, y al menos un centenar de personas con heridas y diferentes afecciones derivadas del estrés experimentado.

Se realizaron talleres comunitarios para establecer estrategias de afrontamiento conjunto, integrando los saberes de los pobladores (baqueanos conocedores del terreno, bomberos y ciudadanos que voluntariamente colaboraron en la asistencia de víctimas de la última inundación) y expertos en las áreas de geografía, hidrología, ingeniería civil y salud pública.

Se prepararon líderes locales en Primera Ayuda Psicológica, se brindaron cursos a psicólogos de la comunidad en técnicas cognitivo conductuales para el tratamiento de afecciones derivadas del estrés y la ansiedad.

Se integraron los saberes académicos y populares utilizando herramientas informáticas de uso masivo (sistema de información georreferenciado Google Earth), elaborándose un protocolo de intervención ante emergencias y catástrofes ambientales a la medida de las capacidades y necesidades de la comunidad.

Palabras clave: GIS, inundaciones, Primera ayuda psicológica, estrés postraumático.

\section{Introducción}

En los últimos diez años el sistema de educación pública argentino ha incorporado a su currículo el uso de herramientas informáticas desde los niveles iniciales de formación. El aumento de la oferta tecnológica a nivel mundial, acompañado de políticas nacionales de igualdad en el acceso a las herramientas informáticas, abre toda una serie nueva de posibilidades en las áreas de capacitación, difusión de información y preparación de comunidades afectadas por el cambio climático para la gestión de riesgo. En diferentes localidades de nuestro país (Argentina) se repartieron notebooks para alumnos de colegios primarios, lo que ha permitido que muchos hogares de clase media y baja contaran por primera vez con tecnología de este tipo al alcance de la mano. 
Sin embargo, el uso de herramientas informáticas como estrategia pedagógica no ha llegado, al menos hoy, a un uso que se extienda más allá de algunos ámbitos académicos específicos. La falta de uso de herramientas que permiten el manejo dinámico de información georreferenciada para la capacitación y la organización de las comunidades afectadas por inundaciones son un claro ejemplo de esto, posiblemente las barreras artificiales que dividen las disciplinas académicas dificulten la incorporación de estas nuevas tecnologías (Tuncay, 2013; Dym y Offen, 2012). Otra posible explicación radica en que la difusión de mapas que especifican zonas vulnerables frente a diferentes tipos de fenómenos, como incendios o inundaciones, podrían ser utilizados con fines distintos a los previstos inicialmente, algunos estados destruyen deliberadamente ciertos mapas por razones de seguridad nacional o control militar (Tuncay, 2013; Craib, 2000).

Una emergencia o catástrofe ambiental puede producir diversos efectos en la salud de una comunidad, tales como trastornos físicos, ansiedad, depresión y otros síntomas del llamado estrés postraumático. Estos efectos pueden reducirse considerablemente si se asiste a las víctimas de forma adecuada desde los primeros instantes de la ocurrencia del fenómeno. De acuerdo al DSM-IV (American Psychiatric Association, 1994), se entiende que tiene lugar una vivencia traumática cuando las personas han experimentado, han sido testigo o se han enfrentado a un suceso que implica la muerte, la amenaza de muerte, heridas graves o riesgo de la integridad física de uno mismo o de terceros. Estas vivencias pueden generar, a posteriori, distintos trastornos mentales como el desorden de estrés postraumático, trastorno adaptativo, trastorno de angustia (ataque de pánico), fobias, trastorno de depresión mayor, abuso y dependencia de sustancias, entre otros.

Cuando las personas se enfrentan en forma continua a amenazas de gran magnitud activan sus áreas cerebrales más primitivas, las que se manifiestan en reacciones comportamentales de lucha, huida o congelamiento (Ursano, McCaughey y Fullerton, 1994; van der Kolk y McFarlane, 1995). En muchas ocasiones estos procesos continúan aunque las personas estén resguardadas de los peligros físicos externos, pudiendo dejar una huella emocional o aprendizaje disfuncional que podría ser la causa de diversas patologías mentales. Ayudar a que las personas se sientan seguras es fundamental para reducir las respuestas biológicas que acompañan al miedo y la ansiedad (Bryant, 2006). Por tales razones es importante que se realicen las intervenciones adecuadas inmediatamente después de este tipo de eventos. La aplicación de protocolos de Primera Ayuda Psicológica y de técnicas cognitivo conductuales para el manejo del estrés y la ansiedad resultan de gran utilidad para la prevención de futuras patologías mentales (Piñeyro y Azzollini, 2015). La psicoterapia cognitivoconductual ha demostrado científicamente tener una adecuada eficacia terapéutica para el tratamiento de los trastornos de ansiedad (Caballo y Vilchez, 2000). Esta psicoterapia se caracteriza por ser breve, trabajar en el presente y con objetivos 
concretos. Por otro lado la Primera ayuda psicológica (PAP) de la Organización Mundial de la Salud - OMS (2012), es una respuesta humana de apoyo a otro ser humano que está sufriendo y que puede necesitar ayuda, la misma constituye una propuesta para tratar de mitigar el daño humano que provocan los acontecimientos graves tales como los desastres ambientales.

Resulta crucial para bajar los niveles de ansiedad aumentar la sensación de control y de previsibilidad de los pobladores ante la amenaza de futuras situaciones de emergencia. Promover la participación de los vecinos en la elaboración de protocolos de gestión de riesgo, no sólo permite recabar información útil de los sucesos, posibilita fundamentalmente el despliegue por parte de la población de estrategias "activas" de afrontamiento que reducen los niveles de estrés.

En este artículo se describen experiencias vinculadas al uso de Sistemas de Información Georreferenciada en el servicio tecnológico brindado por el Centro de Investigaciones Sociales y Humanas para la Defensa al Municipio de El Rodeo.

\section{Metodología}

\section{Diseño}

A través de un servicio tecnológico, brindado por el Instituto Universitario del Ejército, se llevó adelante un estudio de campo en un marco de trabajo de investigaciónacción, por medio del cual se elaboró un diagnóstico psicosocial de la comunidad de El Rodeo (Catamarca), implementándose diversas medidas de intervención como capacitaciones, talleres comunitarios, encuestas domiciliarias, relevamiento de zonas inundables, grupos focales con participación de bomberos, policías y agentes de salud y de defensa civil.

\section{Sujetos}

Expertos en hidrología y geografía de la Universidad Nacional de Catamarca, psicólogos, docentes e investigadores del Ejército Argentino, integrantes del cuartel de bomberos, de la policía, representantes de Defensa Civil de la ciudad de Catamarca, representantes de la iglesia, del municipio, del hospital y vecinos de la comunidad de El Rodeo (Catamarca).

\section{Instrumentos}

Imágenes satelitales de Google Earth, entrevistas abiertas, grupos focales.

\section{Procedimientos}

Se efectuó un trabajo de campo en el que investigadores en ciencias sociales del Ejército Argentino se instalaron durante dos semanas en la localidad. En una prime- 
ra etapa se incorporó al equipo de trabajo 15 asistentes sociales de la Universidad Nacional de Catamarca, junto a ellos se recorrió casa por casa para detectar y elaborar un listado de personas afectadas con síntomas de estrés postraumático y otros trastornos de ansiedad derivados del evento. A su vez se capacitó a psicólogos locales en técnicas cognitivo-conductuales para que puedan brindar un tratamiento breve y eficaz a las personas afectadas por estos trastornos.

Simultáneamente se armaron talleres comunitarios para el intercambio entre los saberes de los pobladores y profesionales expertos en el área sobre la inundabilidad del terreno, para lograr acuerdos y poder establecer zonas seguras, vías de escape y necesidades de asistencia de salud entre otros temas. Por otro lado, se capacitaron bomberos voluntarios locales en Primera ayuda psicológica para que cuenten con protocolos eficaces de asistencia a víctimas de emergencias y catástrofes ambientales en los primeros instantes de la crisis que ocurre durante las operaciones de rescate. Se transfirieron protocolos breves y específicos en Primera ayuda psicológica para la comunicación y el manejo de personas en estado catatónico o histérico, los cuales promueven la actividad de áreas cerebrales implicadas en la toma de decisiones como el lóbulo frontal e inhiben la actividad de otras áreas ligadas a la emoción como la amígdala, disminuyendo así la posibilidad de que se consolide un aprendizaje disfuncional o huella traumática que desencadene un posterior trastorno de estrés postraumático.

En una segunda etapa de intervención se efectuaron reuniones con representantes de las principales instituciones implicadas en la gestión de riesgo (policía, bomberos, hospital local, defensa civil, iglesia) para elaborar un documento base sobre un protocolo de gestión de riesgo ante nuevas inundaciones por crecida del río Ambato, para promover la discusión, resolución de conflictos, establecer acuerdos y responsabilidades se utilizó como herramienta de apoyo las imágenes satelitales de la localidad provistas por Google Earth, las cuales fueron proyectadas a través de un cañón.

En estas reuniones los integrantes de las diferentes instituciones aportaron información relevante sobre la inundabilidad del terreno, zonas seguras, posibles lugares de evacuación, transitabilidad de los caminos, iluminación pública y necesidad de luces de emergencia. Una vez logrado el acuerdo de las partes, se volcó la información resultante en el mapa satelital en forma de capas; una que especifica los cuatro lugares elegidos como centros para refugiados, otra que especifica las diferentes zonas inundables y la zona de trabajo (área de responsabilidad) de bomberos, policía y defensa civil, otra que identifica las calles que requieren instalación de iluminación pública y luces de emergencia, una última que especifica las rutas de evacuación. Finalmente, se elaboró un documento base que se apoya en esta información para establecer un protocolo de gestión de riesgo ante nuevas inundaciones. 


\section{Análisis de datos}

Se efectuaron diversos análisis cualitativos de las entrevistas domiciliarias utilizando el software Atlas.ti.

Se organizaron grupos focales con expertos de diversas áreas y miembros de la comunidad para extraer información relevante sobre la noche de la inundación, la iluminación pública, la transitabilidad del terreno y el accionar de las instituciones en las tareas de evacuación y rescaten de víctimas.

Con la información recopilada en el GIS (Figura 1) se elaboró un documento base para el establecimiento de un protocolo de gestión de riesgo ante inundaciones que se ajusta a los recursos disponibles, la distribución de la población y características del terreno.

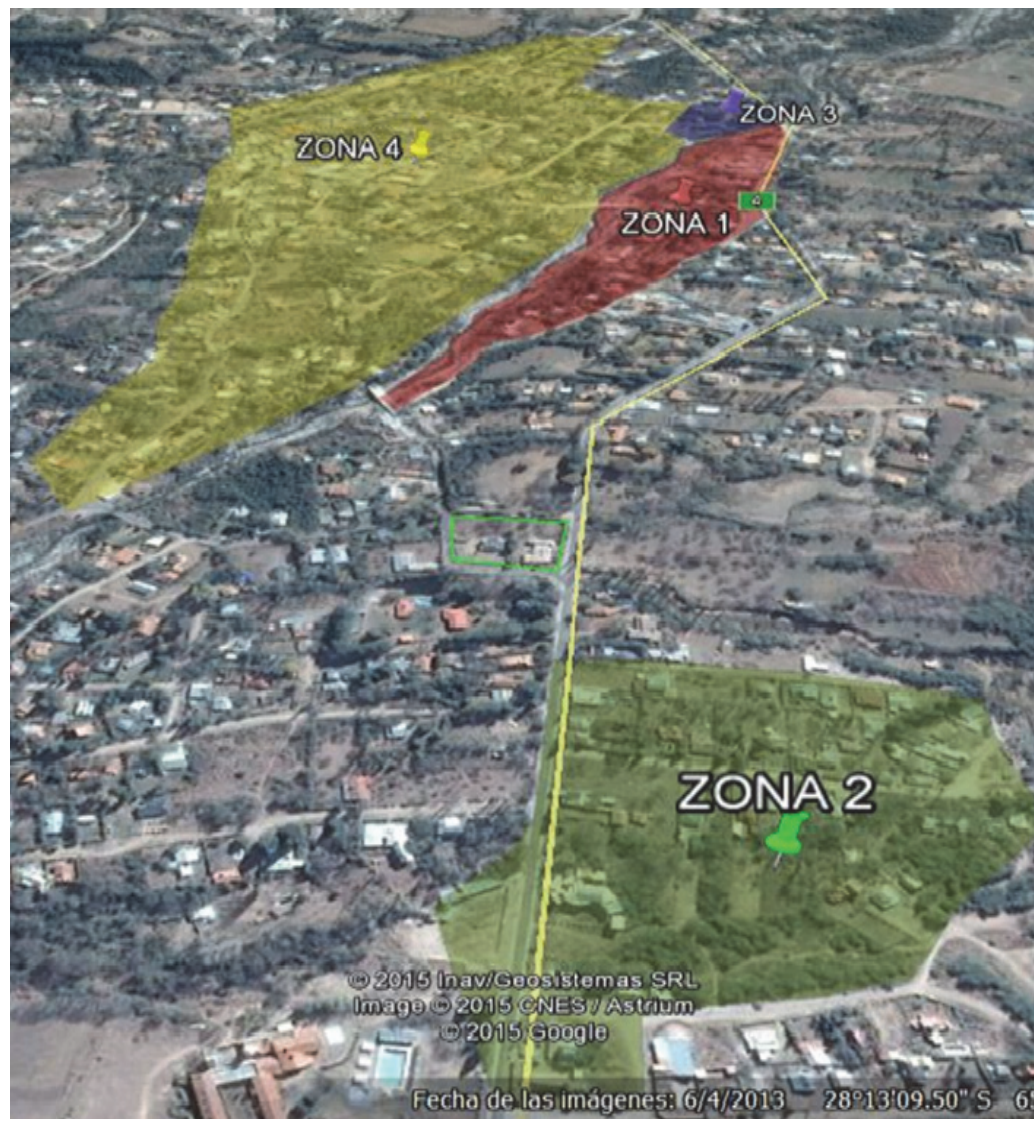

Figura 1: GIS elaborado con información sobre las zonas inundables suministrada por vecinos utilizando Google Earth.

Elaboración propia 2015. 


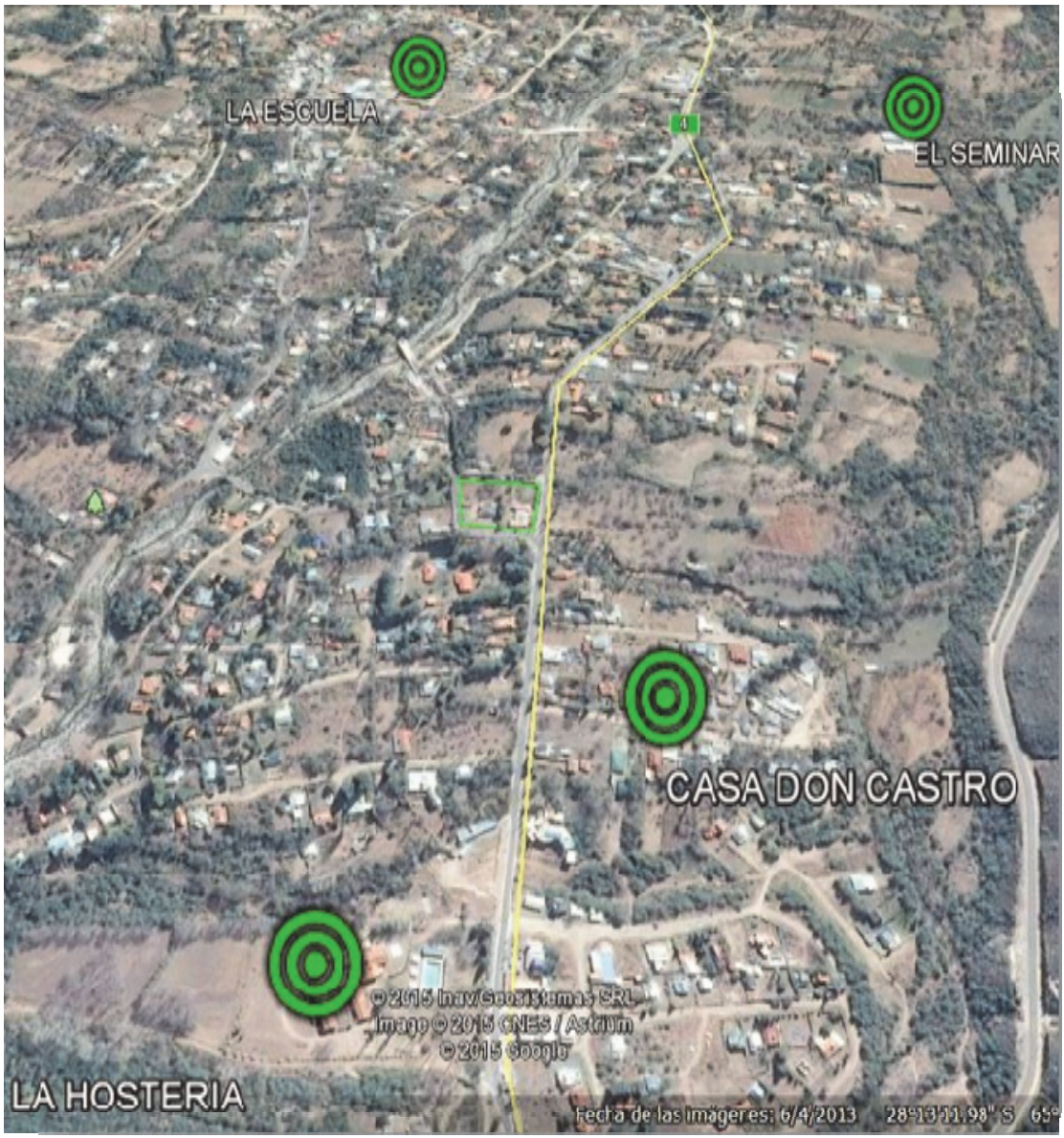

Figura 2. GIS elaborado con información sobre las zonas seguras suministrada por vecinos utilizando Google Earth.

Elaboración propia, 2015.

\section{Resultados y conclusiones}

La inundación del 23 de enero de 2014 afectó a un gran número de personas, tanto turistas habituales como habitantes de El Rodeo. Aproximadamente seis personas de cada 100 quedaron afectadas con algún trastorno de ansiedad. Los entrevistados evaluaron que alrededor de seis personas de cada 10 vivenciaron un miedo intenso durante la inundación. Los miedos se asocian a lo sucedido pero también a lo que podría volver a ocurrir. Ante las situaciones extremas, la sensación de pérdida de control deriva en un fuerte sentimiento de desvalimiento. 


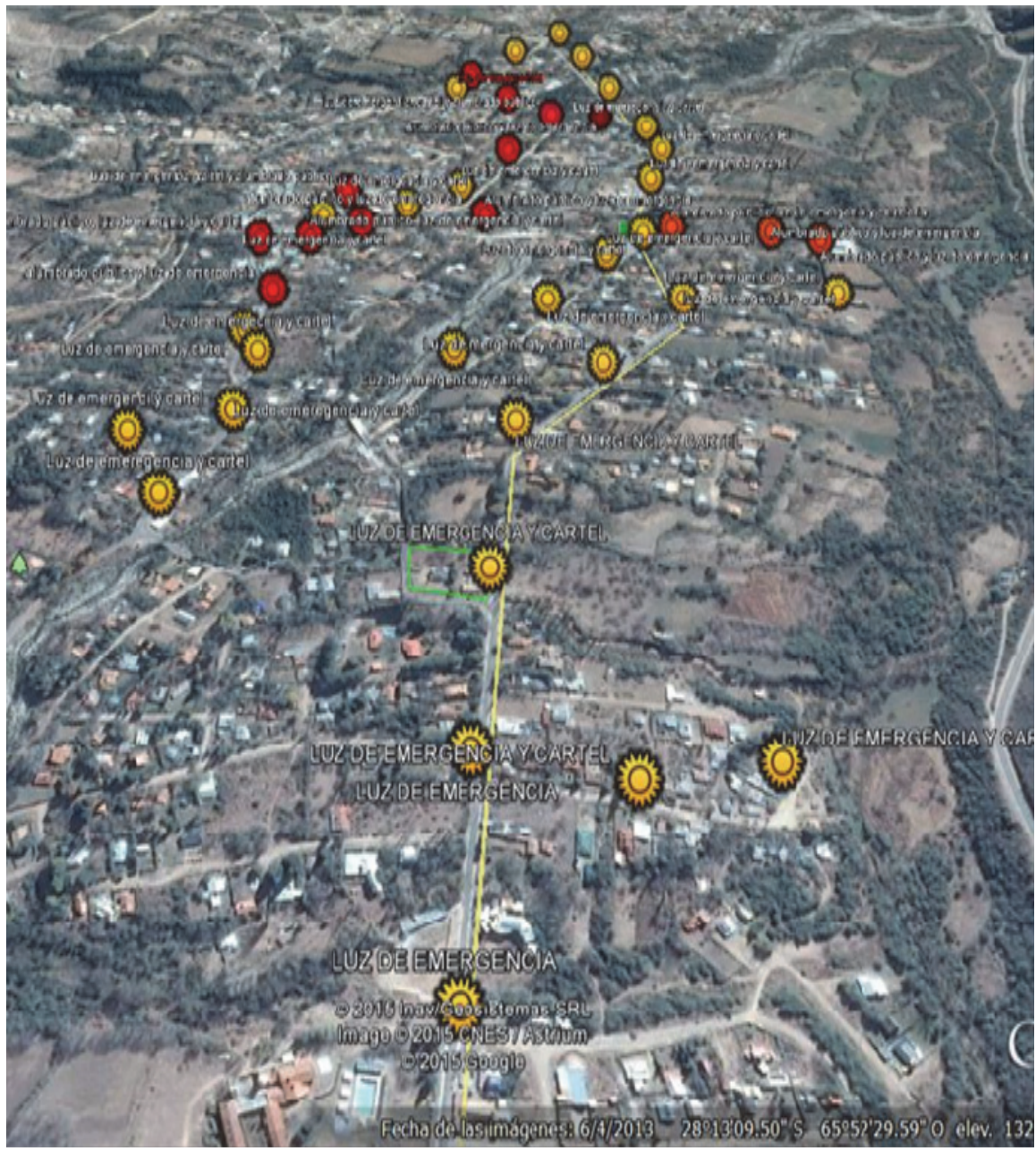

Figura 3. GIS elaborado con información sobre la ubicación donde deben instalarse luces de emergencia (amarillo) y alumbrado público (rojo) suministrada por vecinos utilizando Google Earth.

Elaboración propia, 2015.

De un análisis preliminar de las entrevistas efectuadas en la primera etapa de intervención (de diagnóstico) a los pobladores y de los grupos focales realizados con vecinos y asistentes sociales entrevistadores, se puede apreciar que existe una desconfianza generalizada hacia los "especialistas" ya que los habitantes priorizan el conocimiento local y pragmático sobre el conocimiento general y teórico, por otro lado se pudo observar un gran escepticismo en que pudieran lograrse los acuerdos necesarios que permitan la elaboración de un protocolo de gestión de 
riesgo. Indagando en las razones se pudo observar que la comunidad se encontraba dividida por sus ideales políticos, vale aclarar que las autoridades del municipio pertenecían a una fuerza política opositora al gobierno provincial y nacional, lo que generaba dos corrientes de opiniones bien diferenciadas en cuanto a las causas y responsabilidades de lo sucedido. Por un lado estaban quienes responsabilizaban al gobierno municipal por la construcción de puentes inadecuados, por el otro los que hablaban de un "boicot" del gobierno provincial para atribuirle las muertes al intendente del municipio y de esta forma poder ganar las próximas elecciones. Esta fragmentación también se notaba en las obras hídricas que el gobierno provincial realizó sobre la cuenca del río (su jurisdicción), sin acuerdo ni participación de las autoridades municipales, con vecinos que estaban a favor y en contra de los trabajos realizados.

En este escenario se generaron talleres comunitarios para integrar a la población, buscando despolitizar el tema, promover una participación activa de los vecinos para generar un aumento en la sensación de control, y complementar los saberes de los vecinos con los de los profesionales expertos.

Propiciar este intercambio debería aumentar el compromiso de la población, la participación, la sensación de control, la confianza en las obras y medidas preventivas ante nuevos sucesos. Nuestras observaciones preliminares indican que la realización de los talleres comunitarios, con la incorporación de herramientas informáticas como Google Earth, generaron un gran avance en este sentido, aunque se deben esperar los análisis estadísticos de estudios longitudinales que corroboren esto.

Se utilizó el software Google Earth para realizar un trabajo de cartografía mediante un sistema de información georreferenciada (GIS), en el que se detallan por capas los lugares de encuentro/evacuación (véase Figura 2), la disposición de luces de emergencia necesarias (véase Figura 3), la ubicación y tipo de cartelería indicativa de los lugares citados para facilitar las tareas de policía, bomberos y defensa civil ante una alerta roja y las diferentes zonas inundables. Esta herramienta informática resultó de gran ayuda para llevar adelante este programa de intervención. Su simpleza para la edición y la calidad de sus imágenes satelitales permitieron integrar la información aportada por vecinos y expertos de una manera rápida y sencilla. $\mathrm{Su}$ utilización en los talleres fue crucial, para lograr en poco tiempo un trabajo grupal ordenado y preciso, esto posibilitó los acuerdos necesarios para la elaboración del protocolo de emergencia.

Se elaboró un documento base que propone un plan de contingencia coordinado entre los distintos actores para dar una respuesta adecuada ante una nueva inundación. El mismo propone un sistema de alarma temprana que le daría a la población el tiempo suficiente para una evacuación ordenada, sin víctimas. Las autoridades locales se comprometieron en trabajar con la comunidad, preparándose mediante simulacros para una posterior utilización efectiva de esta herramienta. 
Finalmente, se recomendó a las autoridades pertinentes toda una serie de acciones que pueden sintetizarse en: la contratación de alguna de las psicólogas que participaron en los talleres y fueron capacitadas para brindar tratamientos breves de trastornos de ansiedad para atender a la población afectada, disponer carteles, alumbrado público y luces de emergencia en los sitios señalados en el GIS. También se recomendó realizar mapas turísticos con las zonas de encuentro/evacuación para entregar a turistas y veraneantes, realizar convenios con las instituciones que funcionarán como lugares de encuentro/evacuación, fomentar y organizar reuniones de la Comisión Local de Riesgo para la elaboración del plan de contingencia definitivo, adquirir grupos electrógenos para colocar en las zonas de encuentro con una modificación mínima a las instalaciones eléctricas, establecer una red de alertas internas para que se avise a los bomberos por dónde viene la creciente, buscar voluntarios para que queden encargados de la evacuación de las personas con algún tipo de discapacidad o con muchos niños, preparar a la comunidad mediante campañas de prevención y capacitar a los profesionales de la salud en técnicas cognitivo conductuales.

En síntesis, la realización de talleres comunitarios con la incorporación de imágenes satelitales resulta de gran utilidad para fomentar el diálogo entre vecinos y expertos, rescatar los saberes populares e integrar los mismos con los académicos. Nuestra experiencia nos indica que en muchos casos la información suministrada por los vecinos sobre la inundación (niveles de agua, transitabilidad de las rutas, lugares seguros, etc.) resultó ser más precisa y relevante que la académica aportada por los expertos.

\section{Bibliografía}

American Psychiatric Association (1994). DSM IV- Diagnostic and Statistical Manual of Mental Disorders, Washington, APA.

Caballo, V. y Vilchez, M. (2000). "El tratamiento de los trastornos de ansiedad a las puertas del siglo XXI", Psicología Conductual, 8(2):173-215.

Craib, R. (2000). "Cartography and power in the conquest and creation of New Spain", Latin American Research Review, 35(1):7-36.

Dym, J. y Offen, K. (2012). "Maps and the Teaching of Latin American History", Hispanic American Historical Review, 92(2):213-244.

Farchi, M. (2013). Seminario "Estrés y Trauma en Situaciones de Catástrofe", rectorado del Instituto de Enseñanza Superior del Ejército, 7-8 de agosto de 2013.

Organización Mundial de la Salud (OMS) (2012). Guía para trabajadores de campo, Nonserial Publications, Ginebra.

Páez, D.; Arroyo, E. y Fernández, I. (1995). Catástrofes, situaciones de riesgo y factores psicosociales, Mapfre Seguridad, 57:43-55. 
Piñeyro, D. y Azzollini, S. (2015). Inundaciones urbanas y cambio climático: recomendaciones para la gestión. Eduardo Fenoglio (comp.), "Intervención psicosocial en los planes de contingencia para catástrofes ambientales", Abrapalabra/Gráfica Bruschi, pp. 125-130.

Tuncay, V.B. (2013). "Reflexiones sobre el uso del material cartográfico como herramienta pedagógica en América Latina: una función marginalizada ante la función estratégico-legal", Apuntes, 26(1):78-87.

Ursano, R.J.; McCaughey, B.G. y Fullerton, C.S. (eds.) (1994). Individual and community responses to trauma and disaster, Cambridge, Cambridge University Press.

Van der Kolk B.A. and McFarlane, A.C. (1995). Traumatic Stress: Human Adaptation to Overwhelming experience, New York, Guilford Press. 